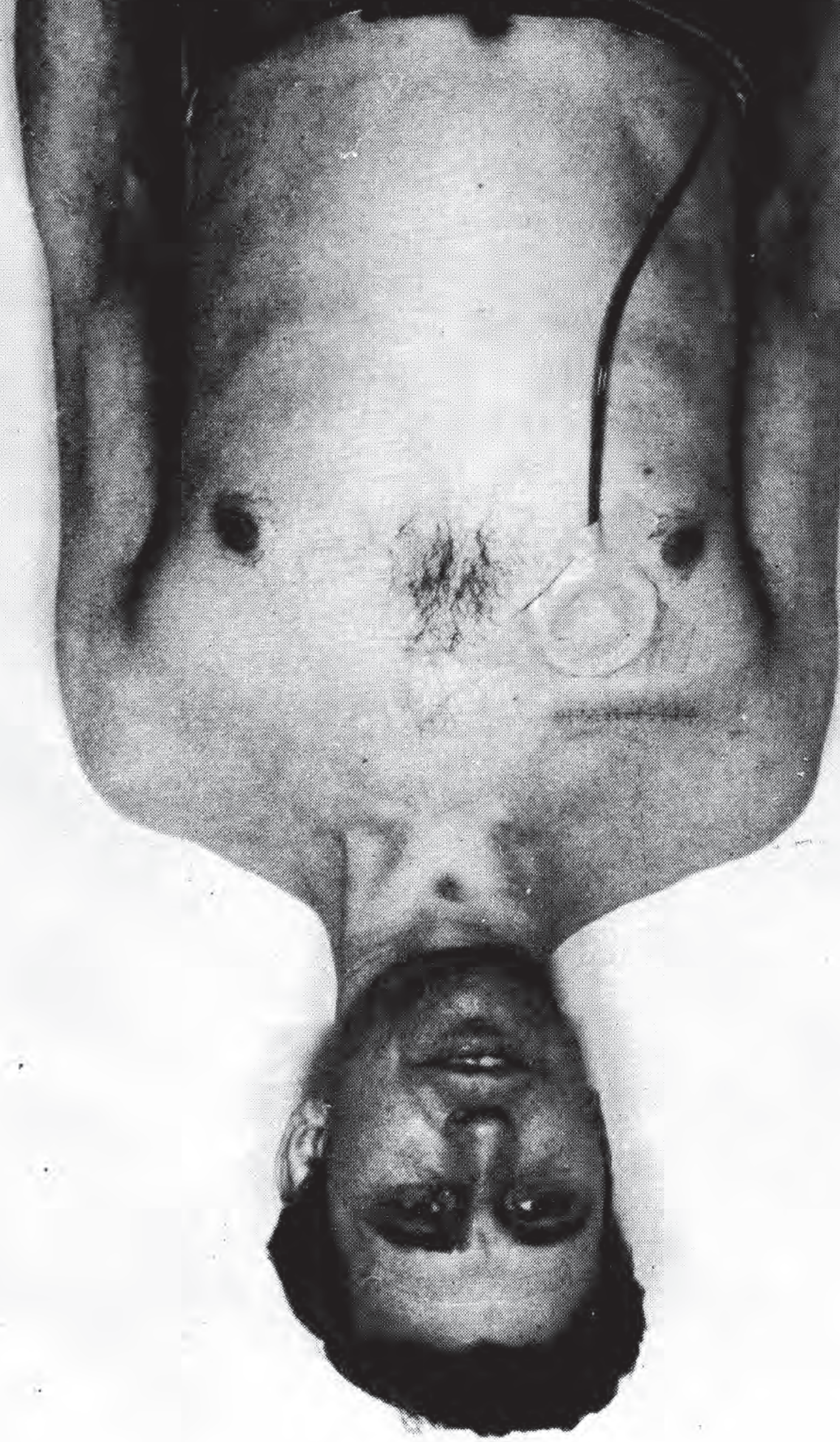




\title{
O FILÓSOFO MUNICIPAL, A SETZUNG E UMA NOVA COALIZÃO LÓGICO-ONTOLÓGICA
}

\author{
MARCOS NOBRE
}

\begin{abstract}
RESUMO
O artigo apresenta uma interpretação de conjunto do percurso intelectual de José Arthur Giannotti até Lições de filosofia primeira (2011), e procura mostrar que, ao abandonar o universo da lógica da Setzung e o projeto de elaborar uma teoria da ilusão necessária, Giannotti não conseguiu mais reencontrar um solo para a crítica, resultado do abandono do campo de forças Kant-Hegel em favor de um campo de forças marcado pelas filosofias de Wittgenstein e Heidegger.
\end{abstract}

PALAVRAS-CHAVE: Filosofia brasileira contemporânea; José Arthur Giannotti; Setzung; Kant-Hegel; Wittgenstein-Heidegger.

\section{ABSTRACT}

The article offers a critical overview of Brazilian philosopher José Arthur Giannotti's intellectual trajectory up to Lições de filosofia primeira (Lessons on First Philosophy, 2011), and attempts to show that, by giving up on the logic of Setzung and on the project of formulating a theory of "socially necessary illusions", Giannotti cannot find any longer the grounds for critique, a result of the abandonment of a theoretical force field built around Kant and Hegel for a different one, centered around Wittgenstein and Heidegger.

KEYWORDS: Contemporary Brazilian Philosophy; José Arthur Giannotti; Setzung; Kant and Hegel; Heidegger and Wittgenstein.

[1] Citações dos livros de Giannotti serão seguidas das abreviaturas: TR (Trabalho e reflexão. Ensaios para uma dialética da sociabilidade. São Paulo: Brasiliense, 1983); AM (Apresentação do mundo. Considerações sobre o pensamento de Ludwig Wittgenstein. São Paulo: Companhia das Letras, 1995); CHM (Certa herança marxista. São Paulo: Companhia das Letras, 2000); e LFP (Lições de filosofia primeira. São Paulo: Companhia das Letras, 2011).

[2] Ver sobre isso a breve introdução à entrevista que fiz com Giannotti para o caderno Eu\&Fim de Semana (Valor Econômico, 27/04/2011, pp. 18-21), em que aproximo Lições do curso de Husserl do inverno de
Éestranho dizer de um livro de Lições que ele condensa o percurso de um intelectual'. Mas, no caso de José Arthur Giannotti, foi exatamente isso o que aconteceu. É somente esse livro que permite entender como conjunto a produção do autor desde a publicação de Trabalho e reflexão, em 1983. É só Lições de filosofia primeira que permite juntar as peças do quebra-cabeça que Giannotti andou montando nas últimas décadas. Nesse livro, pode-se encontrar também a última etapa de um ajuste de contas ainda mais antigo, de seis décadas, com a filosofia de Edmund Husserl, que deveria ter sido o tema do doutorado de 1953, afinal dedicado à lógica de John Stuart Mill².

Não se trata, portanto, de um volume sem mais "introdutório" à filosofia e à sua história, um "manual", ainda que tenha preocupações, digamos, didático-pedagógicas. Ou seja, está presente no livro a tentativa de exporo mais claramente possível o pensamento dos autores examinados; 
mas o fato é que seu procedimento construtivo (do surgimento da questão fundamental do "ser" à crise da metafísica) faz com que sua estrutura se aproxime mais do Martin Heidegger de Introduçãoà metafísica do que de um livro didático no sentido usual do termo. O que, claro, mostra também que Giannotti não entende o "didático" da maneira usual.

As peças do quebra-cabeça teórico de Giannotti desde a década de 1960 são basicamente as mesmas duas peças clássicas: uma lógica e uma ontologia, unidas em dobradiça. Na posição do problema e na busca da dobradiça a unir as palavras e as coisas, o "filósofo municipal" não difere muito de "filósofos mundiais" como Michel Foucault, um seu contemporâneo também egresso da tradição fenomenológica. Chega a ser estranho que Giannotti não tenha se referido mais extensamente ao pensamento de Foucault em seus escritos, ainda que a formulação que dá aos problemas seja diversa. Mas, para o que me interessa aqui, importa ressaltar apenas aquilo que os diferencia, o elemento que ainda falta para completar o esquema de Giannotti e que se encontra ausente em Foucault (que, também nesse déficit, repete Heidegger): o requisito exigente de uma teoria da ilusão necessária.

Giannotti tomou para si a tarefa de pensar uma dobradiça lógico-ontológica que funciona em falso não por boniteza, mas por precisão. Ao contrário de muito filósofo mundial de tradição fenomenológica, tomou para si a tarefa adicional de explodir o esquema fenomenológico husserliano com o que há de mais essencial e de mais refinado no pensamento de Karl Marx: um conceito de crítica enraizado na prática cotidiana das ilusões necessárias que estruturam a complexa cadeia de valorização do capital. Uma precisão de imprecisão necessária, aquela própria do capital.

Mas não foi apenas por isso que Trabalho e reflexão se tornou uma referência para a Teoria Crítica no Brasil. As razões são muitas. Vou me restringir às duas que considero as mais salientes. Em primeiro lugar, ao tomar o pensamento de Marx como fio condutor a alinhavar esses três elementos - lógica, ontologia e ilusão necessária -, Giannotti pôde também prolongar sua crítica à maneira tradicional como as disciplinas das ciências sociais vinham elaborando os temas contemporâneos. Foram criticados em suas limitações, por exemplo, o behaviorismo de B. F. Skinner, a sociologia compreensiva de Max Weber, o cognitivismo de Jean Piaget, a teoria dos atos de fala de J. L. Austin e de John Searle, o Friedrich Engels da Dialética da natureza. E essa crítica à Teoria Tradicional influente em seu tempo se liga de maneira mais geral a uma atitude "antivoga" ou "antivaga", que, com conhecimento de causa ( $e$ isso faz toda a diferença, dado o histórico nacional nesse caso), pretende receber criticamente as diferentes modas teóricas que assolam com frequência a vida intelectual do país 3 . Nesse sentido, tornou-se um modelo duradouro para nossa discussão municipal.
1923-24, publicado justamente com o nome de "Filosofia primeira". Na entrevista, Giannotti se autodeclara "filósofo municipal".
[3] Ver sobre isso a entrevista de Giannottiem Nobre, Marcos e Rêgo, José Márcio. Conversas com filósofos brasileiros. São Paulo: Editora 34, 2000, especialmente pp. 98-99. 
Em segundo lugar, o livro sustenta de maneira obsessiva sua oposição à cisão entre "ser" e "dever ser" e se aferra de maneira peculiar ao adágio do modus in rebus. Porque a própria cisão entre o que é e o que deve ser tem de abstrair do objeto para ser estabelecida, tem de esquecer a medida que o objeto carrega nele mesmo, vale dizer, tem de abstrair do fato de que também a norma, também o "dever ser",é um momento inalienável do "ser" do objeto. Tampouco aceita o expediente fácil - e tão em voga na filosofia contemporânea atual - de dizer que o problema se resolve fazendo da cisão uma distinção meramente analítica: porque é a distinção mesma que obscurece a apresentação dos processos efetivos de medida que produzem a objetividade.

Essa configuração teórica foi possível porque Giannotti ancorou sua teoria da medida no processo social de trabalho, tomado como núcleo irradiador de diferentes formas da sociabilidade capitalista. Mas, se o modelo lembra o de História e consciência de classe - já que, no caso de Lukács, a "forma mercadoria" desempenha o papel de "centro irradiador" da sociabilidade - o resultado é bastante diverso. Porque, em Trabalho e reflexão, não se trata de pensar que se espraia unicamente o formalismo próprio da reificação, formalismo que se chocaria, no limite, segundo Lukács, com os requisitos mais vitais de existência do operário. Sem abrir mão da premissa da dominação social do capital, o livro projeta uma variedade surpreendente de arranjos sociais reais e possíveis dos processos de medida - vale dizer, de processos efetivos de produção e de troca em sua reconstrução racional. E, com isso, assinala também que as fissuras na lógica da reprodução social são muito mais variadas do que a da contraposição exclusiva de capital e trabalho. O que, não por último, vai dar também em uma visão muito mais complexa e cheia de nuances da política. Não apenas pelo papel central que passa a desempenhar o Estado, mas pela possibilidade de a política se infiltrar de diferentes maneiras e em diferentes arranjos nas tramas da lógica da reprodução social.

Encontrar a multiplicidade sob a máscara da identidade, mostrar que a realidade social se perde no exato momento em que é pensada a partir de elementos tomados como idênticos ("capital", "mercado", "classes sociais", "Estado", e assim por diante), ao mesmo tempo que mostra que essa lógica da identidade é a lógica mesma da ilusão socialmente necessária, tudo isso não foi mero aggiornamento de Marx e do marxismo. Não foi pouco produzir uma ontologia (social) capaz de reconduzir a ideia de que identidades a um tempo conceituais e práticas apagam as marcas de sua produção a uma lógica mais geral de formação de identidades sociais que opera segundo ilusões socialmente necessárias. Porque apresentar esse vínculo em seu processo de construção é o mesmo que mostrar que a lógica da redução forçada da 
multiplicidade à unidade mostra a lógica mesma do funcionamento do poder sob o capitalismo tardio.

Não que com isso Giannotti tenha passado a compartilhar com Theodor W. Adorno uma crítica da ilusão necessária de identidade, ou algo assim. Pelo contrário. Muitos anos depois, em Certa herança marxista, de 2000 , ficou atestada sua rejeição a Adorno, cujo "discurso infeliz", segundo Giannotti, "nada mais pode além de incansavelmente tentar enxergar a face oculta da Lua" 4 . E essa rejeição é ditada não apenas por diferenças teóricas quanto à compreensão da identidade, mas pela diretriz de não perder de vista o novo que pode sempre irromper no velho estabelecido. Ainda assim, não deixa de ser estranho que Giannotti não reconheça nesse embate o quanto um dia esteve próximo de Adorno. Nem o quanto, depois da publicação de Trabalho e reflexão, buscou em F. W. J. Schelling, como Adorno antes dele, uma saída para escapar à lógica de identidade que caracteriza mais amplamente o idealismo alemão dentro do campo de forças do próprio idealismo alemão.

Seja como for, trata-se, até Trabalho e reflexão, de uma lógica da multiplicidade que só pode ser reconstruída em sua complexidade se trazida à unidade de maneira reflexionante - seguindo o modelo do Marx do manuscrito de Para a crítica da economia política, segundo o qual o "concreto é concreto porque síntese de muitas determinações, unidade do múltiplo, portanto"5. Ainda na pista de Marx, Trabalho e reflexão reconstrói o complexo processo de que o concreto é o resultado, de maneira a mostrar que, no cotidiano da dominação, esse processo é reduzido à unidade de maneira violenta, com base em ilusões necessárias - um exercício de poder que se apresenta não em sua efetiva trama reflexionante, mas como um processo determinante, justamente.

A ruptura com esse quadro de pensamento vai se dar quando Giannotti se mostra insatisfeito com a reconstrução desse processo reflexionante. O transbordamento que levou para além desse esquema teórico foi descrito pelo próprio autor da seguinte maneira nas "Considerações iniciais" de Apresentação do mundo, de 1995. No mesmo ano da publicação de Trabalho e reflexão, em 1983, Balthazar Barbosa já tinha lhe colocado a pulga atrás da orelha ao aproximar uma das noções centrais do livro, a noção de "esquema operatório" ${ }^{6}$, do "jogo de linguagem não verbal" de Ludwig Wittgenstein. Ao perseguir essa indicação, deu-se conta de que o lado lógico da dobradiça tinha perdido o pé e devia ser refeito - o que, em um modelo que pensa conjuntamente lógica e ontologia, significa que o pé ontológico também tinha vacilado. Isso tudo tem que ver ainda, em sentido mais amplo, com uma obsessão antiga, com uma espécie de postulado do autor: o de que uma filosofia que não está à altura da lógica do seu tempo é simplesmente uma má filosofia7. E ele se deu conta de que a lógica
[4] CHM, p. 172 .

[5] Coleção "Os Economistas". São Paulo: Abril Cultural, 1982, p. 14 .

[6] Cf. especialmente TR, pp. 48-57.

[7] Como se sabe, esse postulado, emversão kantiana, é o da lógica formal como "fio condutor" para a lógica transcendental. Aversão de Giannotti é mais próxima da formulação do postulado dada por Husserl (e que Giannotti também reencontra, em outro nível, em Wittgenstein): a lógica formal já é lógica transcendental (cf., por exemplo, AM, p. 15). 
de Trabalho e reflexão estava aquém do que já tinha sido desenvolvido antes por Wittgenstein.

A experiência dessa reformulação fez com que percebesse que os elementos de sua reflexão não podiam mais ser pensados à maneira da lógica da "medida", por complexa que fosse. Para retomar o início, era a dobradiça a ligar lógica e ontologia que tinha enferrujado. E o agente corrosivo, no caso, vinha de um pressuposto teórico importante e não problematizado de Trabalho e reflexão que acabou subindo à superfície:uma concepção de linguagem ainda por demais impregnada de fenomenologia. A partir desse momento, o que se tem é algo mais próximo de um sistema de referências internas obrigatórias entre elementos lógicos e elementos ontológicos. É a busca de um sistema de referências como esse que vai orientar o trabalho de Giannotti a partir de então e que pode ser resumido na busca de algo como uma "teoria do juízo", em lugar da unidade reflexionante da "medida". Não por último porque, segundo a autocrítica de Giannotti, a própria ideia de "reflexão" estava aquém dos desenvolvimentos já realizados por Wittgenstein.

A partir desse momento, ao se livrar do que ele via como uma tralha fenomenológica, Giannotti se desvencilhou do último fardo do idealismo alemão que ainda lhe pesava: o de uma lógica da "posição", da Setzung. E isso significou ao mesmo tempo abandonar o campo de forças que vai de Immanuel Kant a G. W. F. Hegel e que leva de volta a Kant. Essa foi a escolha filosófica decisiva depois da publicação de Trabalho e reflexão. E é a escolha que prevalece até hoje nos escritos de Giannotti.

O abandono do universo conceitual da Setzung está intimamente ligado à aceitação do diagnóstico de Heidegger apresentado em uma constelação de textos pertencentes ao universo de Ser e tempo, de 1927 (especialmente o curso do mesmo ano, Problemas fundamentais da fenomenologia), e, subsidiariamente, em um texto de 1961, "A tese de Kant sobre o ser", do volume Marcas do caminho (Wegmarken). Comparando Kant e Heidegger, Lições mostra como o primeiro tem na Setzung, na posição, sua compreensão fundamental da existência: "a existência provém de um ato de pensar ponente que, para Kant, está ligado ao eu transcendental. Esta casa vem a ser sendo graças a um eu ponente que vem a ser ente enquanto é. A existência não categoriza a casa, mas resulta de um ato desse eu que, no fundo, é de todos. Desse modo, a existência não é uma propriedade do objeto, mas um modo pelo qual elée posto" 8 .

Assim caracterizada, a filosofia kantiana teria aberto a porta a partir da qual, no caminho que leva até Marx, passando por Hegel e o idealismo alemão, o sujeito moderno ganharia progressivamente o lugar de criador ou engendrador do mundo e da história. Não cabe aqui re- 
tomar todo o argumento a partir do qual Giannotti, apoiado em Heidegger, irá desmontar essa pretensão demiúrgica do sujeito moderno, moldado pela virada prática própria do pós-kantismo. Tampouco se trata, pelo momento, de questionar as consequências de tal diagnóstico heideggeriano, mesmo que sua liquidação do sujeito moderno traga pouco mais do que uma crítica abstrata da técnica e da ciência contemporâneas. O que cabeélembrar que foi em um universo teórico ainda marcado pela lógica da Setzung que Giannotti desenvolveu sua reflexão até pelo menos meados da década de 1980. E que, para entender seu posicionamento atual, é preciso reconstruir esse seu percurso que leva de Kant a Marx, até a caracterização da Setzung como processo de trabalho, bem como tentar apresentar a peculiarversão que dela deu em Trabalho e reflexão.

Para tanto, começo tomando um atalho. Trabalho e reflexão foi talvez o primeiro livro no país a esboçar uma crítica ao neokantismo de John Rawls, algo que pode ter passado despercebido dado o então quase completo ineditismo do autor de Uma teoria da justiça, de 1971, em um país de economia fechada e cujo sistema universitário estava ainda em processo de consolidação. Ainda que não seja explícito a esse respeito, transparece na referência de Giannotti a Rawls algo de uma crítica ao contratualismo em geral. Mas vou pegar a deixa em um outro sentido.

Contrariamente a Rawls e aos "modernos neokantianos" em geral, Giannotti prefere "trilhar outros caminhos, pensar ao nível do próprio 'juízo' a determinação recíproca entre o ato efetivo e a meta visada. Daí ser mister, primeiramente, deixar de tomar esse ato como parte duma atividade deliberativa, tramando regras desde o início, para acompanhá-lo tão só na sua efetividade diante do alvo. No lugar de juízo, comportamentos orientados. Em seguida, abandonamos o pressuposto de que essa regra mantém sua identidade indeformável durante o processo" ${ }^{9}$. Não deixa de ser interessante notar como a equação vai se inverter na década seguinte: no lugar de comportamentos orientados, juízo - sendo que juízo já virá sem necessidade de aspas. Mas o relevante aqui é insistir em que a "efetividade" do "ato" é o que permite sua reconstrução em pensamento de tal maneira que possa ser capturado em seu processo social de medida e em sua inscrição na teia de ilusões socialmente necessárias à sua produção. Na versão que deu Marx da Setzung, da posição, essa efetividade do ato remete à ideia de um sujeito que põe o mundo segundo um esquema em que a representação do ato não coincide com a sua posição efetiva. Esse sujeito, o proletariado, ao unir, por meio da ação política, esses dois momentos objetivamente cindidos, torna-se classe.

Não é à toa, portanto, que caiba ao trabalho "o papel genético-transcendental", "sendo o único comportamento que de imediato visa transformar em ente o objeto que representa"10. Não é igualmente

[9] TR, p.303.

[10] Idem, p. 304 . 
[11] Idem, p. 305 .

[12] Idem, p. 308 .

[13] Idem, p.310. casual, nesse contexto, que o trabalho seja "força produtiva por excelência; visa transformar a coisa num valor de uso para o homem, tomando-a como se fosse apenas um ente a ser adequado ao consumo, mas terminando por convertê-la num objeto reflexionante"11. Pois essa reconstrução do trabalho como matriz "genético-transcendental" dos comportamentos sociais em geral segue de perto a apropriação por Marx do idealismo alemão e da lógica da Setzung, que é interpretada por Giannotti mediante a análise dos dois passos do processo que considera fundamentais: a representação e a medida.

No esquema de Trabalho e reflexão, essa análise em dois momentos abre a fissura cotidianamente preenchida pelas ilusões socialmente necessárias, aquela entre a "medida representada" ea "medida efetiva": "Frisamos desde logo que o processo de trabalho não persiste sem um momento representativo, mas para que o alvo seja reiteradamente anteposto precisa ser medido. No entanto, abre-se uma diferença entre a medida representada e a medida efetiva, pois só esta última demanda um padrão estável de funcionamento" ${ }^{12}$. Encontra-se aqui tanto uma apresentação sintética da "dialética da sociabilidade" de Giannotti quanto a outra ponta de sua crítica ao neokantismo do final do século XX, exemplarmente representado por Rawls. De modo que não é por acaso que seja igualmente esse o momento de apontar o lugar da política, como "representação do todo, sua encenação", "que põe no palco o interesse comum como se este não atravessasse as vicissitudes de transformação das coisas e dos homens" ${ }^{13}$.

É a articulação de Trabalho e reflexão em torno do trabalho como matriz "genético-transcendental" que garante à crítica o acesso às diferentes dimensões sociais, não por último à política. A mesma matriz que põe Giannotti em continuidade do que se chamou aqui de lógica da Setzung, segundo a qual a crítica em sentido enfático só se tornou possível no momento em que, com Kant e com o idealismo alemão, a prática passou a ter ao menos primado sobre a teoria, uma lógica que alcançou sua forma mais radical e mais elaborada no conceito de trabalho de Marx.

O peculiar da "dialética da sociabilidade" de Giannotti até Trabalho e reflexão está em ter reelaborado o conceito de trabalho de Marx segundo uma lógica mais geral, segundo a lógica da medida, cuja matriz está na medida própria do valor, padrão que se espraia pelo conjunto das relações sociais. A reelaboração de Giannotti conta não apenas com a reconstrução dos termos sofisticados em que Marx pensou a medida do valor, mas também com uma atualização segundo a lógica político-estatal de formação dovalor própria do capitalismo da segunda metade do século xx. Uma atualização que permitiu mostrar que os processos de medida são tão variados quanto irredutíveis sem mais unicamente à lógica da produção de mercadorias e da troca capitalista. 
E isso não apenas porque, no próprio Marx, o caminho que leva da forma mercadoria à forma capital, passando pela forma dinheiro, contém já um campo de variação dos processos de medida por si mesmo notável. Também porque tentar produzir algo como uma teoria da medida que dê conta desse campo de variação permite mostrar um campo de variação de formas de sociabilidade (e de oportunidades de ação, portanto) igualmente de amplo espectro, o que funciona como antídoto para a tentação de uma uniformização e homogeneização das formas de vida que, no final das contas, serve apenas para simplificar a tarefa do crítico. E, segundo o diagnóstico subjacente, traz à luz uma variedade de processos de exercício do poder que se dão em níveis, dimensões e contextos igualmente diversos - que apenas de maneira reflexionante podem ser trazidos à unidade própria da lógica da medida. Conta para isso com uma aliança com a antropologia social contemporânea, capaz de fornecer instrumentos para pensar uma complexificação do processo de divisão do trabalho e da troca à altura das sociedades do então chamado "capitalismo tardio", o que permitiu em não poucos momentos uma apresentação inédita de conceitos tão centrais como "troca" ou "modo de produção". Apresentados para criticar e corrigir por vezes o próprio Marx, inclusive.

Nesse sentido, encontrar acordo ou desacordo "no nível do juízo" pressupõe um acordo ou desacordo prévio sobre processos sociais concretos de medida, entendidos, por sua vez, em referência a uma identidade comum que tem de ser pensada como produzida de maneira reflexionante e segundo a fissura estrutural entre "medida representada" e "medida efetiva". Uma identidade, portanto, que não pode ser pressuposta à maneira da ontologia clássica ou mesmo do individualismo possessivo da modernidade liberal. Colocado por si mesmo contra a parede, Giannotti não hesita em tomar uma posição radical a esse respeito: "Preferimos o radicalismo que nega qualquer identidade prévia indeformável"14.

A partir da segunda metade da década de 1980, Giannotti começa a encontrar dificuldades na articulação desses dois pontos fundamentais. $\mathrm{O}$ acordo ou desacordo em torno da medida não pode mais tomar a formação do valor como padrão, mesmo com todas as correções e restruturações do então chamado "capitalismo tardio". E essa mudança de diagnóstico do tempo corresponde a uma mudança decisiva na teoria: a descoberta de que a "identidade" visada a cada caso pelo acordo ou desacordo em torno da "medida" pressupunha uma filosofia da identidade que já não podia ser sustentada. Por mais sofisticada que tenha sido a apropriação por Marx da herança do idealismo alemão e por mais sofisticadas que fossem as interpretações contemporâneas em torno da formação do valor, havia ainda um lodo de fundo que ti- 
nha permanecido intocado, resumido aqui pela lógica da Setzung. Agitado, esse lodo tornou a água turva. Mas, para Giannotti, produziu um espelho mais adequado para que a sociedade atual pudesseencontrar seu rosto no reflexo. Não só como filosofia teórica, mas ainda na moral e na estética.

Para retornar uma vez mais ao início: as peças do quebra-cabeça teórico de Giannotti são basicamente uma lógica e uma ontologia, unidas em dobradiça e funcionando segundo ilusões socialmente necessárias. Isso me parece representar a linha fundamental de continuidade dos escritos de Giannotti. E, se está correta a reconstrução de como esses elementos se articulam em Trabalho e reflexão, a consequência é a de que a alteração na caracterização de um desses elementos leva necessariamente a uma reconfiguração mais ampla de sua articulação.

Ocorre que ao buscar recompor a unidade de Trabalho e reflexão em um nível que julga mais sofisticado, mais preciso e mais complexo, Giannotti tenta fazê-lo com instrumentos que o impedem estruturalmente de alcançar tal objetivo. Ou, pelo menos, alcançar um dos elementos fundamentais: aquele de uma teoria da ilusão necessária. Essa é uma das maneiras de apresentar a interpretação de conjunto do percurso de Giannotti desenvolvida aqui. O que é o mesmo que dizer que, ao abandonar o universo da lógica da Setzung, Giannotti não conseguiu mais reencontrar um solo para a crítica. Uma deficiência estrutural que resulta do abandono do campo de forças Kant-Hegel em favor de um campo de forças marcado pelas filosofias de Wittgenstein e Heidegger.

Ao recorrer a Marx em Certa herança marxista, Giannotti conseguiu a duras penas mapear (não mais que isso) os problemas a serem enfrentados com vistas a recompor o que poderia vir a ser posteriormente uma teoria da ilusão necessária. Foi apenas com o capítulo de Heidegger de Lições de filosofia primeira que alcançou esboçar algo como uma "crítica da inautenticidade" que parece pretender dar lastro a uma retomada de sua intenção crítica anterior. Em Lições, Giannotti refere essa nova gramática da autenticidade à ontologia de matriz wittgensteiniana que já havia desenvolvido em Apresentação do mundo. Para desenvolver esse novo campo de referências teóricas de maneira consistente, termina já anunciando um novo livro que tratará apenas desses contrapontos Heidegger/Wittgenstein. Mas, mesmo antes da publicação desse novo volume, já é possível dizer, com base no que é oferecido em Lições, que não vai conseguir alcançar a teoria da ilusão necessária sem a qual a articulação entre os dois momentos funciona de maneira acrítica. Porque não se vê como tal teoria seria alcançável nos termos em que se constrói hoje a reflexão de Giannotti. Vejamos isso um pouco mais de perto. 
A rearticulação teórica realizada em Apresentação do mundo já dava conta de uma maneira nova de rearranjar a própria história da filosofia. O pensamento de Marx deixou ali de ser o ponto de referência a organizar a história da teoria, à maneira de um antes e de um depois. O que significa, ao mesmo tempo, que a modernidade de que o pensamento de Marx é um emblema deixa de ser o negativo privilegiado sobre o qual se decalca o momento presente. Uma modernidade que, do ponto de vista teórico, ainda se movia em um ambiente de pensamento demarcado pela crítica de Hegel a Kant e pela possibilidade de mobilizar uma metacrítica de inspiração kantiana à filosofia de Hegel. A transformação materialista desse campo de forças teórico por Marx levou à categoria de "ilusão socialmente necessária", síntese e suma da sua versão da teoria da subjetividade moderna moldada a partir do centro filosófico do idealismo alemão, da Setzung.

Lições é o livro que consuma a virada iniciada em Apresentação do mundo.É o momento em que Giannotti expõe claramente não apenas o seu abandono do paradigma da Setzung em sua versão mais avançada, aquela de Marx, mas vai ainda além: o paradigma da Setzung passou a ser ele mesmo um bloqueio à compreensão do momento presente. De modo que sua própria compreensão da modernidade passa agora por dinamitar esse padrão pressuposto de subjetividade e de sociabilidade, que considera a partir de então por demais limitado para o entendimento do presente. A produção até Trabalho e reflexão passa a ser lida pelo próprio Giannotti como um conjunto de tentativas ainda canhestras de alcançar o nível de complexidade teórica e o de exposição próprios dos escritos posteriores a Apresentação do mundo.

Vale a pena acompanhar um pouco mais de perto esse movimento, já desenhado claramente em 1995, nas "Considerações iniciais" de Apresentação do mundo. Em primeiro lugar, a tradução do problema da medida na nova forma de apresentação gramatical: "O tema da medida [...] se traduz no tema do critério, em suma, de como se pode afirmarlegitimamente que tal expressão ou ação seja correta ou incorreta. Noutras palavras, no que consiste um jogo de linguagem? Se a descrição das regras de um jogo constitui proposições de essência determinando os tipos de objeto com que lida esse sistema linguístico, o problema duma ontologia se resolve numa investigação gramatical, no amplo sentido que Wittgenstein empresta a esse termo"15.

Em segundo lugar, Giannotti tem claro que, se essa reviravolta lhe permite uma exposição que entende mais sofisticada do que com a obtida anteriormente com a noção de "esquema operatório", o objetivo reafirmado de produzir uma teoria da ilusão socialmente necessária não pode ser alcançado com o auxílio de Wittgenstein: "O que restou, pois, de meu antigo projeto duma ontologia do ser social? Depurado de seus encalhes fenomenológicos e de alguns ecos 
[16] Idem, ibidem.

[17] Idem, ibidem.

[18] LFP, p. 14 .

[19] Idem, p. 373 .

[20] Idem, p. 15. ainda lukácsianos, o compromisso de continuar a examinar formas de sociabilidade, vale dizer, sua gramática, notadamente a lógica do sistema capitalista. Mas para isso é preciso tomar enormes distâncias do trabalho realizado por Wittgenstein, e tentar mostrar que os erros metafísicos, em que necessariamente cai o pensamento ao longo de seu percurso, podem servir de base para formas alienadas de sociabilidade. Se a verdade não se constitui numa combinação de opiniões, mas se firma no processo de julgar levando em conta os resultados de sua própria atividade, não pode esse consenso verdadeiro tramar-se na base duma ilusão necessária?"16.

Por fim, Giannotti remete a reconstrução dessa trama ilusória a uma política que já não pode se reivindicar de um primado da prática: "a inautenticidade do modo de produção capitalista não se esboroa em virtude da análise lógica das ilusões necessárias em que ele se baseia. Se de fato a filosofia deixa tudo como está é porque perdemos o horizonte iluminista, a esperança de que o trabalho filosófico se transforme em prática revolucionária. Mas esse retraimento das pretensões da filosofia traz em consequência a revalorização da prática política"17.

Esse é o ponto central do percurso: a constatação da "perda" do "horizonte iluminista" é solidária do abandono da lógica da Setzung. Segundo seu diagnóstico de tempo, essa "perda" significa necessariamente um abandono do primado da prática. O que, entretanto, torna inteiramente indeterminado o que poderia vir a ser, como diz o texto, uma "revalorização da prática política", já que era justamente o universo da Setzung aquele que, como se viu acima a propósito de Trabalho e reflexão, não submetia a política seja às abstrações representativas como as de um Rawls, seja a dedutivismos teóricos de quaisquer matizes. E essa constatação de Giannotti se radicaliza a tal ponto que, em Lições, ele vai chegar mesmo a afirmar que "todos os movimentos revolucionários, depois de um momento glorioso de libertação, pouco a pouco caíram na vala comum do totalitarismo" ${ }^{18}$.

O diagnóstico de tempo de Giannotti afirma que a união de teoriae prática (mesmo a do melhor marxismo) conduz inevitavelmente a totalitarismos. Mais ainda, afirma que os "filósofos marxistas mais abertos às questões da filosofia da lógica ficaram balançando entre Kante Hegel sem chegar a uma crítica radical de seus pressupostos lógicos. E assim tudo contribuiu para que o pensamento filosófico marxista se transformasse numa langue de bois, puro psitacismo"19. Ou seja, o único caminho para tentar afastar essas consequências inevitavelmente nefastas é abandonar o universo da Setzung. Giannotti aconselha voltar aos textos originais de Marx "antes de armar um novo discurso sobre a 'emancipação', a 'democracia radical' e outras palavras de ordem" 20 . Dito de outra maneira: toda tentativa de se colocar em continuidade com a tradição da Setzung é hoje filosoficamente rala (já que não esta- 
ria à altura dos desafios lógicos do tempo) e politicamente ingênua (quando não explicitamente perigosa).

Giannotti constrói um diagnóstico de tempo em que não há nenhuma possibilidade de reformulação frutífera do universo da Setzung. A alternativa que apresenta é entre a estultice (que pode até acabar em totalitarismo) ou sua própria posição. Só que aceitar a posição proposta por Giannotti implica abandonar justamente o "horizonte iluminista" no qual a regência do primado da prática permitiu primeiramente a crítica no sentido enfático que adquiriu por fim em Marx. Não apenas Giannotti não encontra mais solo para a construção de uma teoria da ilusão socialmente necessária e para uma crítica da alienação: ele subdetermina a própria política.

Ao me opor a esse diagnóstico e à alternativa magra que dele resulta não pretendo de maneira alguma dizer que o problema não seja real, que a lógica da Setzung, mesmo em sua versão marxista mais refinada não tenha caducado. Antes pelo contrário. Ao criticar esse universo de pensamento, Giannotti toca no nervo exposto dessa tradição e mostra convincentemente muitos de seus limites, o que torna a leitura de seus escritos tanto mais necessária. Quero dizer apenas que é equívoca a identificação entre o esfumaçamento do horizonte em que a teoria era solidária do apoio concreto da práxis em uma classe revolucionária com um pretenso desaparecimento do "horizonte iluminista" enquanto tal. Porque abandonar o horizonte iluminista, abandonar o universo da Setzung em sentido amplo significa sim abandonar o primado da prática que primeiro permitiu a crítica social em sentido enfático. E não há razão para estreitar a alternativa teórica de tal maneira que a escolha seja entre o proletariado como sujeito-objeto idêntico ou o abandono do primado da prática e do horizonte iluminista. Ou, pelo menos, as razões que dá Giannotti para estabelecer uma tal alternativa magra são bem pouco convincentes.

É certo que nenhuma das tentativas no século xx de continuar pensando no interior do universo da Setzung de um ponto de vista crítico ecoam positivamente na reflexão de Giannotti. A obra de maturidade de Theodor W. Adorno é dedicada toda ela a elaborar a possibilidade de um pensamento que escape a essa lógica de um sujeito ponente no interior mesmo desse universo teórico, buscando nos domínios da própria lógica da Setzung as brechas para o que ele chamou, em sua Dialética negativa, de "primazia do objeto". Movimento difícil que, em Adorno, faz da "crítica imanente" não uma "comparação do conceito com o conceituado em vista da sua unidade (atual ou potencial), mas não identidade de conceito e conceituado em vista da ilusão necessária de sua identidade real" 21 .Já se viu aqui a opinião pouco prestigiosa que tem Giannotti da filosofia de Adorno.
[21] Nobre, M. A dialética negativa de Theodor W. Adorno. A ontologia do estado falso. São Paulo: Iluminuras/ Fapesp, 1998, p. 175. 
[22] In: Montero, Paula e Comin, Alvaro (orgs.). Mão e contramão. Rio de Janeiro: Globo, 2009.
[23] Lições dedica algum tempo a explicar as razões pelas quais Heideggerse desinteressou inteiramente da lógica formal (cf. LFP, especialmente pp. 317-18), mas sem tirar disso nenhuma consequência contra o próprio Heidegger.

[24] Como, por exemplo, no "Apêndice" a Apresentação do mundo (especialmente, pp. 298-300), em que Giannotti concorda com a interpretação de Heidegger sobre a diferença em Kant, entre realidade (Realität) e efetividade (Wirklichkeit) como uma diferença que inaugura a lógica mesma da Setzung: uma diferença entre "posição relativa" e "posição absoluta" que seria borrada ao se seguir as "trilhas íngremes" que conduzem a Marx, passando por Hegel. E, ao mesmo tempo, como já mencionado, critica a lógica heideggeriana que daí se segue a partir de Wittgenstein.
Uma outra tentativa de reformulação do "horizonte iluminista" pode ser encontrada nos escritos de Jürgen Habermas, que critica a lógica da Setzung segundo a ideia de que toda "filosofia do sujeito" se enreda em dificuldades teóricas e práticas insolúveis no interior desse modelo de pensamento (e, nesse sentido, é uma crítica que se aplica também ao próprio Adorno). A "virada intersubjetiva" proposta por Habermas visa manter, entretanto, a primazia da prática na ideia de uma precedência da "ação comunicativa", procurando reformular a ideia de crítica no confronto entre potenciais comunicativos liberados pela modernidade e seu bloqueio por uma lógica sistêmica não por último representada pelo capitalismo tardio e sua institucionalização. Com isso, torna-se possível produzir referenciais críticos como os da "colonização do mundo da vida pelo sistema" ou mesmo o de uma "comunicação sistematicamente distorcida". Para constatar a opinião pouco prestigiosa que tem Giannotti dessa proposta de Habermas, basta consultar, entre muitos exemplos, o artigo "Habermas: mão e contramão" 22 , em que se vê que nem mesmo transformado intersubjetivamente nesses termos o universo da Setzung poderia, segundo Giannotti, ser prolongado.

Evoquei aqui rapidamente as reflexões de Adorno e de Habermas não para afirmar que representem posições mais plausíveis ou mesmo corretas quando comparadas à posição de Giannotti - mesmo porque são dois exemplos que entendo antagônicos e irredutíveis a uma unidade, dois modelos críticos bastante diferentes. Os exemplos de Adorno e de Habermas surgem aqui apenas como contraste, para mostrar que a alternativa proposta por Giannotti é por demais estreita. É claro que não lhe escapou a necessidade de criticar tanto Adorno quanto Habermas como possibilidades equivocadas de prolongamento da lógica da Setzung, mesmo que transformada. Aliás, as críticas que Giannotti dirige a tentativas como essas estão calcadas justamente na ideia de que são apenas prolongamentos mal disfarçados (e mal-ajambrados) da Setzung.

E, no entanto, quando se retoma a argumentação de Giannotti referente à impossibilidade de prolongar a lógica da Setzung seja por que caminho for, esbarramos sempre no já mencionado postulado de que a lógica moderna a teria tornado inevitavelmente caduca. Ou em uma formulação de matriz heideggeriana - incompatível com o referido postulado, ressalte-se - de que a metafísica do sujeito teria encoberto "a pergunta pelo ser" exatamente pelo recurso à lógica da Setzung. Acontece que Giannotti nem aplica ao próprio Heidegger o dito postulado ${ }^{23}$, nem aceita todas as consequências filosóficas que advêm da ideia motriz do esquecimento do $\operatorname{ser}^{24}$.

Esse estado de coisas mostra, por sua vez, um relativo subdesenvolvimento do diagnóstico de tempo de Giannotti, representado por 
sua utilização - como se não fossem argumentos incompatíveis, lembre-se uma vez mais - seja de seu postulado lógico, seja de um diagnóstico de Heidegger que não é aceito em todas as suas consequências. Isso talvez explique por que, todas as vezes que é confrontado com o problema de apresentar uma teoria da ilusão necessária, Giannotti remeta essa apresentação à política e que esta, por sua vez, permaneça subdeterminada em seus escritos posteriores a Apresentação do mundo. Trata-se de fato de uma mera remissão:fica-se sempreà espera da descrição gramatical - e "o problema duma ontologia se resolve numa investigação gramatical, no amplo sentido que Wittgenstein empresta a esse termo" 25 , é bom sempre lembrar - , que, enfim, mostrará como a política se tece de fato segundo uma trama que comporta necessariamente alienação.

Considerando o conjunto da argumentação desenvolvida até aqui, não é de surpreender que Lições adote a estratégia de tomar as duas pontas da história: a progressiva formação da metafísica na Grécia Antiga e sua dissolução de longa duração a partir do século XIX em diante. Para tanto, passa por alto não apenas a filosofia medieval (examina-se unicamente a patrística, tomando Agostinho como emblema), mas, especialmente, toda a metafísica do sujeito típica da modernidade. $\mathrm{Ou}$ seja, passa por alto a moderna metafísica do sujeito que tem como uma de suas cristalizações emblemáticas a filosofia da Setzung, própria do idealismo alemão.

Ao executar o salto mortal de Agostinho a Nietzsche, o que Giannotti salta no seu livro é a formação do sujeito moderno. Seja segundo a história de longa duração do nascimento do indivíduo moderno na filosofia medieval, seja na formulação mais direta do sujeito como fonte de toda representação. É verdade que, se não tivesse dado esse salto, Giannotti teria defrontado com o trabalho irrealizável de apresentar uma história da filosofia "completa" e academicamente informada em todos os seus momentos. Nas suas palavras: "Como se percebe, não pretendo escrever uma história da metafísica. Deixo um buraco enorme, que vai da filosofia medieval, pulando o racionalismo clássico e toda a teoria do conhecimento, à crítica que se desenvolve a partir de Kant. É possível falar da filosofia sem estudar Tomás de Aquino, Descartes, Hume, Kant, e assim por diante? Não, mas se eu enveredasse por esse percurso não teria escrito esse livro, que não pretende ser global nem apresentar um panorama completo dos problemas levantados" 26 .

[26] LFP, P. 12.

Mas, ao mesmo tempo, ao executar o salto, Giannotti se esquivou da tarefa de enfrentar a ambivalência própria de um Hegel em relação à filosofia grega, uma espécie de emblema de toda a filosofia da Setzung. Nas palavras de Gérard Lebrun em sua interpretação da 
[27] A paciência do conceito: ensaio sobre o discurso hegeliano. São Paulo: Editora da UNESP, 2006, p. 191 (nota).

[28] Falando sobre a ausência de Leibniz, Giannotti a justifica não apenas como uma falha "por economia", mas acrescenta explicitamente o elemento aqui mencionado: "quis evitar toda a problemática do sujeito, e a mônada é antes de tudo um sujeito absolutamente representante equerente" (LFP, p. 12).

[29] LFP, pp. 370-71.

[30] Ainda a propósito da armação geral do livro, é de notar que o capítulo sobre Wittgenstein é relativamente subdesenvolvido, dada sua posição de ponto de fuga da reconstrução. Mas isso se deve ao fato de que a exposição se encontra ali em estado de alta condensação, não comparável nesse sentido com qualquer dos demais capítulos.

[31] Estrutura que fica clara quando Giannotti justifica a exclusão de Kant com base na premissa de que "Kant apenas leu, com pequenos retoques, a lógica formal e escolar de seu tempo, a partir da atividade ponente do eu transcendental". E, ao mesmo tempo, explicita, na sequência, a razão para a exclusão de todo o universo da Setzung, incluindo-se aí o prolongamento no marxismo e na Teoria Crítica: "Do mesmo modo, seus [de Kant] sucessores, os idealistas alemães, ficaram confinados a essas fronteiras. Fichte, Schelling, Hegel não escapam desse abraço. Nem o marxismo e a Teoria Crítica atual. Isso explica por que tenho tentado escapar desse circuito, que não amplia o âmbito do relacionamento do logos e do ser, do ser e do ente, além de uma lógica formal incapaz de compreender o novo estatuto lógico das estruturas matemáticas" (LFP, p. 11). filosofia hegeliana: "Se os gregos estavam mais afastados da consumação do Saber (ausência da Subjetividade), estavam igualmente a mil léguas de sua deformação subjetiva (ausência da Subjetividade finitizada)"27. O efeito dessa supressão é o de construir uma imagem da metafísica que se conecta diretamente com sua longa crise terminal, já a partir da crítica de Nietzsche. Com isso, a crise da metafísica deixa de ser apresentada como crise da metafísica do sujeito e, em especial, da filosofia da Setzung ${ }^{28}$.

O que não impede de observar que o capítulo sobre Nietzsche parece simplesmente deslocado. Nisso, aliás, não está sozinho: também o seu correspondente simétrico, o capítulo sobre Agostinho, parece não encontrar o seu devido lugar na armação geral do livro. Uma observação que não afeta em nada o mérito dos capítulos como apresentação dessas duas filosofias, pelo contrário. Só não se vê como eles entram no esquema geral traçado. A impressão que fica é a de que Giannotti sentiu o peso de saltar quinze séculos da história da filosofia e optou por uma passagem que não é mais do que verbal: o primeiro filósofo cristão contra o primeiro filósofo anticristão. Com a diferença de que o caso de Nietzsche tem pelo menos a função pedagógica de espantalho para afastar tentativas vitalistas de variados matizes, o que resulta na reafirmação da superioridade das filosofias tanto de Heidegger quanto de Wittgenstein: "se para falar com sentido é preciso levar em conta uma gramática, vale dizer, regras articuladas entre si que mostram como se deve falar, é preciso ter todo cuidado para não cair num outro abismo, representado por Nietzsche. Afirmar que toda regra depende de uma avaliação anterior a qualquer bipolaridade, sendo unicamente motivada por uma força vital, termina por considerar as mais diversas funções da linguagem, a afirmação da vida como potência" 29 .

Feita a reserva e a ressalva, a estrutura do livro sublinha em cada um dos seus passos as teses solidárias que o atravessam de uma ponta a outra ${ }^{3}$. Em primeiro lugar, G. Frege ocupa o lugar daquele que, abrindo dimensões antes impensáveis para a lógica, coloca desafios para a filosofia para os quais qualquer metafísica está desaparelhada, em especial uma metafísica do sujeito. Frege, aliás, estava ele próprio desaparelhado em termos filosóficos para dar conta de suas descobertas lógicas. Talvez não custe lembrar aqui uma vez mais o postulado implícito de Giannotti de que verdadeiras revoluções lógicas inauguram desafios filosóficos de longa duração. Tal foi o caso de Aristóteles. Tal foi o caso de Frege. Não por acaso, os dois pontos de apoio, as duas margens a partir das quais Lições lança suas pontes ${ }^{31}$. Com a especificidade de que a revolução lógica do século XIX não teve no seu autor-emblema, em Frege, o seu filósofo, como se pode dizer de Aristóteles. Não por último pelo peculiar platonismo de Frege. 
Em segundo lugar, Husserl seria justamente aquele que primeiro teria se dado conta da gigantesca dimensão do desafio aberto por Frege. O seu fracasso em produzir uma filosofia à altura dessa revolução lógica é muito mais do que um fracasso: é um fracasso exemplar. E é exatamente por essa razão que a fenomenologia se torna, na apresentação de Giannotti, a porta de entrada por excelência da filosofia contemporânea. Mesmo representando uma tentativa insuficiente de dissolver a metafísica diante dos desafios colocados por Frege, Husserl formulou primeiramente os termos em que as novas tarefas se colocavam. Algo como um tradutor das exigências postas pela revolução de Frege, sem ter conseguido estar à altura ele mesmo de respondê-las.

Em terceiro lugar, por fim, Heidegger e Wittgenstein aparecem com os pensadores que finalmente conseguiram colocar o seu tempo em pensamento. Mas, da perspectiva de Giannoti, só se pode fazer essa afirmação tomando os dois pensadores em uma espécie de coalizão. Dois pensadores de que, apesar de contemporâneos, não se tem notícia de terem sequer lido um ao outro, muito menos debatido. $\mathrm{O}$ que quer dizer que se trata, em boa medida, de uma coalizão artificial, construída por Giannotti, cujo objetivo, nos termos de Lições, seria o seguinte: "Muito se tem falado na virada linguística (linguistic turn) da filosofia ocidental, que deixa de ser filosofia da representação para ser filosofia do discurso. Nossa estratégia é tentar capturar esse movimento quase no final do percurso, a crise da fenomenologia, representada por Heidegger, e a crise da filosofia analítica de que Wittgenstein é o maior exemplo. Esperamos assim estudar as duas correntes que engrossaram e criticaram o campo de batalha onde se têm cruzado as grandes correntes filosóficas do século Xx. E aquelas do século XXI que ainda não começaram"32.

[32] LFP, p. 295.

Falo aqui em uma coalizão construída artificialmente porque tudo se passa como se, no esquema de Giannotti, Heidegger fosse corrigido por Wittgenstein e este fosse por sua vez suplementado por uma "moral da autenticidade" de matriz heideggeriana de que carece. Ao final, tem-se um Heidegger filtrado pelo coador da filosofia terapêutica de Wittgenstein, ou seja, à altura da lógica e da ontologia mais avançadas de que se dispõe. O mais curioso desse esquema, no entanto, é que o movimento teórico não é realizado de uma vez por todas, como se, decantada a borra ainda por demais fenomenológica (ou "hermenêutica", como se queira) da filosofia heideggeriana, o resultado fosse enfim a enunciação positiva de uma nova filosofia, propriamente giannottiana. Pelo contrário. Trata-se de uma coalizão exatamente porque o processo de filtragem tem de ser feito a cada vez, a propósito de cada descrição gramatical, a propósito da apresentação de cada "ontologia regional", se ainda for permitido usar a expressão. A "materialidade" 
[33] AM, pp. 199-204.

[34] Idem, p. 203.

[35] Cf. LFP, p. 323. de cada descrição gramatical, de cada "ontologia regional" não pode se fiar na fundação em uma "ontologia formal". Em suma, Giannotti montou um esquema de "checks and balances" filosófico, no interior do qual questões lógico-ontológicas podem ser adequadamente tratadas. Um sistema que exige um vaivém permanente entre Heidegger e Wittgenstein, sem nenhum ponto de parada ou fixação.

Desde Apresentação do mundo Giannotti já havia criticado a filosofia de Heidegger a partir de uma perspectiva wittgensteiniana.A perspectiva construtivista da coalizão montada por Giannotti é claramente apresentada na seção "Expressão e bipolaridade lógica"33, cuja súmula enuncia: "O que Wittgenstein poderia ter dito da lógica heideggeriana". E seu sentido geral pode ser encontrado na seguinte passagem: “Wittgenstein substitui o 'algo como algo' heideggeriano, estrutura ontológica de qualquer expressão e fundamento de qualquer forma de linguagem, pela gramática de 'ver algo como algo', um jogo de linguagem que se aprende quando se aprende a transformar sinais em signos"34. Giannotti encontrou em Wittgenstein a correção do "como hermenêutico" heideggeriano, anterior ao próprio enunciado35. Vale dizer que enxergou na lógica heideggeriana mais uma oportunidade terapêutica, de correção de erros gramaticais.

Ao mesmo tempo, Giannotti não encontra em Wittgenstein um correspondente adequado do encaixe representado pelo Dasein heideggeriano, dobradiça lógico-ontológica sem a qual o quebra-cabeça não pode ser composto para ainda permitir algum tipo de crítica do existente. Parece ser por essa razão que o Dasein retorna com força insuspeitada em Lições. A citação que se faz necessária aqui é longa, mas igualmente significativa: "Heidegger considera, em todos os entes que se nos apresentam finalizados em nossos relacionamentos com o mundo, uma juntura de algo com algo, uma remissão objetivante e objetivada como uma possibilidade do Dasein, como se fosse uma dobradiça, uma parte que tem a outra por fim, esta por sua vez segurando-se na outra, encontrando nela seu fim, sua meta, sua razão deser assim. É nessa duplicidade do envio, da remissão de algo a algo, que os signos se nos apresentam, de sorte que tanto se mostram nela quanto fazem transparecer um modo pelo qual algo que se dá como algo. A dobradiça apresenta a dimensão ontológica do ente manejável significante e cria o espaço no qual vai se ancorar o enunciado que diz algo como algo. Antes da forma tradicional da predicação, 'algo como algo', reside um travejamento de junções ligando os entes instrumentais. $O$ manejável se mostra no que ele é propriamente, mas então inserido numa totalidade instrumental: na casa onde eu moro, na cidade em que habito, no mundo em que me situo. Desde logo o mundo se me apresenta como mundo, meu mundo assim como para os outros e, por isso mesmo, emergindo como logos" 36 . Esse "mundo", depurado 
da necessidade de uma "explicação antepredicativa da verdade" 37 pela terapia wittgensteiniana, liberto pela análise gramatical da "estrutura ontológica do 'algo como algo"' 38 , está na base da mais recente configuração do quebra-cabeça de Giannotti.

Além disso,é também, em última instância, esse sistema de "checks and balances" lógico-ontológico aquele que organiza a reconstrução da história da filosofia apresentada em Lições. Uma reconstrução que, como já mencionado, procura evitar a ambiguidade de Hegel em relação ao mundo grego, apontada antes com a ajuda de Lebrun. De maneira mais geral, caracteriza uma estratégia teórica de se esquivar da imagem do mundo grego produzida pelo idealismo alemão, segundo a qual a verdadeira "realização do saber" só poderia se dar com uma filosofia da Setzung. Porque, no caso de Giannotti,é a Setzung que cabe evitar.

E, no entanto, foi a lógica da Setzung que organizou sua leitura de Marx desde a década de 1960 e que deu suporte e substância ao fio condutor da lógica (do capital) à ontologia (social) que se consubstanciou no problema da medida, espinha dorsal dos trabalhos de Giannotti até Trabalho e reflexão. Por isso, é possível dizer que, a partir desse momento, o objetivo primordial de Giannotti foi evitar o que se poderia chamar de uma "filosofia nos limites da simples reflexão". Incluindo aí os seus próprios escritos até a década de 1980.

Mas o elemento wittgensteiniano da regra e da gramática da regra em que Giannotti passa a desenvolver seu trabalho a partir de fins da década de 1980 não se mostrou suficiente para resolver os problemas que se colocou. Talvez seja mais preciso dizer que o próprio problema ainda não estava suficientemente claro para ele mesmo antes dos anos 2000. É nesse sentido mais preciso que se pode dizer que, em Lições de filosofia primeira, Giannotti finalmente alcançou a formulação que buscava desde os anos 1980 .

Porque, se se toma a transformação do problema da medida em um caso - ainda que um caso especial, um caso-regra - do problema mais geral da descrição gramatical, em Apresentação do mundo, de 1995, vê-se que é ainda a lógica da Setzung que domina, mesmo que de maneira negativa. Basta ver a enorme importância que tem Kant nesse livro. O que, evidentemente, também é sintomático: não se trata mais de Marx, tampouco de Hegel. Ee é sintomático porque, ao recuar até Kant, Giannotti também está recuando até um momento em que a Setzung ainda guardava a ambiguidade de poder se mover mais livremente entre as palavras e as coisas. Quer dizer, esse primeiro movimento de recuo em relação à Setzung significa também um movimento rumo a uma teoria do juízo. Foi essa abertura em relação ao pesado fardo da Setzung que foi seguida nas obras poste- 
riores. E não há por que deixar de anunciar aqui de outra maneira e mais uma vez a outra ponta desse caminho, posta em Lições: para se livrar do fardo da Setzung é preciso também abandonar a lógica mesma da realização da razão, a lógica da efetividade (a Wirklichkeit) que lhe é inseparável. Mesmo na versão altamente sofisticada que lhe deu Marx.

Foi isso o que Giannotti deixou claro em Certa herança marxista. Esse duro acerto de contas com Marx e com os seus próprios escritos até a década de 1980 foi uma crítica sem tréguas da lógica da Setzung. É também por essa razão que Giannotti insiste tanto em textos habitualmente pouco frequentados e pouco examinados de Marx. É por isso que Giannotti garimpa sacadas nos Grundrisse; é por isso que desde o início tem por pressuposta a interpretação de que Marx fracassou em seu intento, de que $O$ capital ficou um livro inacabado por boas razões. Porque não se trata apenas de criticar Marx (e de criticar a si mesmo), mas de ressaltar aqueles aspectos de Marx que não podem ser reduzidos à lógica da Setzung.

É como se Giannotti tivesse ele mesmo refeito o caminho de Marx e finalmente compreendido por que Marx (e ele mesmo) tinham de fracassar. Pode ser que haja algo dele mesmo na caracterização que dá dos "filósofos marxistas mais abertos às questões da filosofia da lógica", que "ficaram balançando entre Kant e Hegel sem chegar a uma crítica radical de seus pressupostos lógicos"39. Nesse sentido, não só Husserl (em Lições), mas também Marx é outro caso de fracasso exemplar. E, no entanto, ocupam posições inteiramente diferentes. Marx fecha uma época: levou ao limite a lógica da Setzung, e o seu fracasso representa o esgotamento desse universo de pensamento. Já Husserl representa uma abertura para o futuro: libertando Kant do fardo da Setzung que a posteridade lhe impôs, a fenomenologia volta-se para uma teoria do juízo que pretende se colocar à altura dos desafios postos por Frege. O papel antes desempenhado por Marx é desempenhado agora pela coalizão lógico-ontológica Wittgenstein-Heidegger. Não é por acaso, portanto, que a Lições ainda vá se seguir um próximo livro, dedicado unicamente à coalizão. E que esse novo livro não vá ter a mesma forma expositiva de Lições, mas uma bem mais próxima de Apresentação do mundo.

Seja como for, o novo livro promete dar conta, se não de uma teoria da ilusão necessária, ao menos do fenômeno da alienação. É pelo menos esse o resultado da crítica a Marx e ao marxismo do final de Lições: "o problema da alienação continua a ser posto praticamente todos os dias: que lógica move certas ações humanas que resultam no contrário do que elas pressupõem quando são deslanchadas?"40.A formulaçãoé um tanto apressada e pouco precisa. Mas o fundamental está em que o problema continua a ser constitutivo do quebra-cabeça de Giannotti. 
Ainda que sua devida apresentação ainda esteja por ser feita nos termos da coalizão lógico-ontológica.

Só que nada indica que o problema da alienação possa ser de fato apresentado nesse novo quadro de pensamento. O que está intimamente ligado, por sua vez, ao abandono do campo de forças da filosofia da Setzung, do campo de forças que se põe entre Kant e Hegel. O preço a pagar por essa estratégia de esquiva é justamente a perda dos instrumentos necessários para construir uma teoria da ilusão socialmente necessária. E a razão é aí trivial. Medida com o metro de uma teoria da ilusão necessária, a filosofia de Heidegger pode fornecer a Giannotti quando muito uma "crítica da técnica", cuja interpretação tem um campo de variação não muito largo, impondo a escolha entre a mera tecnofobia ou uma crítica romântica da modernidade, calcada, talvez, na noção de "cuidado" (Sorge)41. Um campo de variação, ressalte-se, que nada tem que ver com o entusiasmo crítico com o desenvolvimento das forças produtivas que Giannotti sempre demonstrou. Do lado de Wittgenstein, a situação não é melhor desse ponto de vista. O filósofo dos jogos de linguagem pode, quando muito, dar base a uma "terapêutica". Ou seja, pode aliviar do fardo da muita metafísica que ainda está impregnada nos usos e abusos da linguagem. Mas nada tem a dizer quando se trata de "sutileza metafísica e manhas teológicas" da "coisa muito complicada" que é a mercadoria em Marx e a política no capitalismo. E esteé o ponto: desde que perdeu o ponto de apoio da Setzung, Giannotti não conseguiu reencontrar a teoria da ilusão socialmente necessária que promete. E, nas formulações posteriores a Apresentação do mundo, isso significa também que não conseguiu reencontrar um lugar para a política, vale dizer, não conseguiu encontrar um ponto de apoio para girar o compasso de uma teoria do direito e da democracia de intenção crítica.

Seja como for, a divisão do trabalho filosófico entre Heidegger e Wittgenstein pressupõe uma unidade lógico-ontológica que não está nem em um nem no outro. Seria possível dizer muito simplesmente que está em Giannotti. De certa maneira, foi o que se tentou indicar aqui, de maneira negativa, a partir do sistema de "checks and balances" lógico-ontológico que permite correções e suplementações nos contrapontos Heidegger/Wittgenstein. Mas buscar uma indicação como essa não significa colocar o ônus da prova nas costas do filósofo municipal, que teria então toda a razão em recusar o encargo de uma apresentação positiva de seu quebra-cabeça. Apresentar, a essa altura do campeonato pós-metafísico, uma nova articulação de lógica e de ontologia da qual Wittgenstein e Heidegger seriam indícios, pontos de apoio e elementos probantes? Uma exigência como essa não seria razoável. Tampouco adequada
[41] A noção de Foucault de "cuidadodesi" étalvezaquela que alcançou os limites de uma tradução crítica possível da "Sorge" heideggeriana, já que os termos histórico-filosóficos em que o fez permitem ao menos descrever dispositivos de controle sociale deixam entrever possibilidades de resistência a eles. Cf. História da sexualidade (três volumes, Rio de Janeiro: Graal, 1984-85) e o curso do Collège de France de 1982, A hermenêutica do sujeito (São Paulo: Martins Fontes, 2004). Cf. também LFP, pp. 132 e330. 
Recebido para publicação

em 30 de maio de 2011 .

\section{NOVOS ESTUDOS}

CEBRAP

90 , julho 2011

pp. $35-55$ para quem não se pretendeu tal objetivo. Mas não há nada de exterior ou de excessivo de cobrar de Giannotti uma "teoria da ilusão necessária", algo que ele sempre colocou como um dos objetivos fundamentais da sua reflexão. E, sob esse aspecto, ele continua em dívida com a municipalidade.

MARCOS NOBRE é professor do departamento de filosofia do IFCH-Unicamp e pesquisador do Cebrap. 